\title{
The role of dietary nucleotides in single-stomached animals
}

\author{
Nadja Sauer, Rainer Mosenthin* and Eva Bauer \\ Institute of Animal Nutrition, University of Hohenheim, 70593 Stuttgart, Germany
}

\section{Abstract}

The transition from liquid to solid feed during weaning results in morphological, histological and microbial changes in the young animal's intestinal tract and often is associated with diarrhoea. The ban of in-feed antibiotics in pig production in the European Union has led to increasing interest in alternatives to overcome weaning-associated problems. Among others, nucleotides may have the potential to alleviate health impairments due to weaning. Nucleotides are natural components of the non-protein fraction of milk and have important effects on the maintenance of health in young animals. Nucleotides and their related metabolic products play key roles in many biological processes and become essential dietary components when endogenous supply is insufficient for normal function. The present review summarises nucleotide composition of milk from different species, the biology of nucleotides and possible effects of dietary nucleotides on intestinal morphology and function, intestinal microbiota, immune function, nutrient metabolism, hepatic morphology and function as well as growth performance. Special attention is given to data available for pigs, and suggestions are made for inclusion of nucleotides in the diet to benefit piglets' health and reduce the consequences accompanying early weaning.

Key words: Gastrointestinal tract: Single-stomached animals: Nucleotides: Pigs

\section{Introduction}

Until 2006, in-feed antibiotics were used to overcome weaning-associated problems in pig production. Nowadays, an interest in antibiotic-free animal production has been established worldwide due to the risk of antibiotic resistance in humans ${ }^{(1)}$. As weaning is accompanied by morphological, histological and microbial changes in the gastrointestinal tract of young mammals ${ }^{(2,3)}$, nutritional strategies are being developed to aid immature animals to overcome weaning-associated problems and withstand infectious diseases. Among others, dietary nucleotides are one group of bioactive agents which may have the potential to diminish challenges related to weaning ${ }^{(4)}$. Nucleotides are naturally present in all foods of animal and vegetable origin ${ }^{(5)}$ but in lower concentrations than in mammalian milk ${ }^{(6)}$. Soluble nucleotides have been determined in milk from various mammals, contributing to as much as $20 \%$ of its non-protein fraction ${ }^{(7)}$. The nucleotide pattern in milk is species-specific, and concentrations vary with stage of lactation. Nucleotides and their metabolic products play key roles in many biological processes, for example, as monomeric units of nucleic acids, in transferring chemical energy, in biosynthetic pathways, as biological regulators and as coenzyme components ${ }^{(8)}$. Although nucleotides are synthesised endogenously, there is also evidence that dietary supplementation with nucleotides may exert beneficial effects both in humans and animals (for reviews, see Carver \& Walker ${ }^{(9)}$ and Taylor-Pickard ${ }^{(10)}$ ). In animals, including pigs and rodents, positive effects on small-intestinal growth and development ${ }^{(11)}$, on intestinal hyperaemia ${ }^{(12)}$, on stimulation of systemic immunity ${ }^{(13)}$ and on hepatic composition ${ }^{(14)}$ have been described. In addition, a protective role in the prevention of diarrhoea in pigs has been reported by Martinez-Puig et $a l^{(15)}$. Accordingly, Gil et al. ${ }^{(16)}$ described in human subjects beneficial effects of supplemental soluble nucleotides on the composition of the faecal microbiota, as measured by an increase in bifidobacteria and lactobacilli. Inconsistent results, however, have been found for small-intestinal disaccharidase activity as influenced by nucleotide supplementation $^{(17,18)}$. However, there are few data on the animals' requirement for exogenous nucleotides, and most of the studies have investigated effects of dietary nucleotides on the immune function in rodents, whereas only limited information exists on the possible role of nucleotides in promoting intestinal health or in stimulating the development of the immune system in other species. The present review summarises data published on nucleotide composition of various food and feed ingredients with special emphasis on milk originating from different species. Furthermore, possible effects of dietary

Abbreviations: CMP, cytosine 5'-monophosphate; IMP, inosine 5'-monophosphate; UMP, uridine 5'-monophosphate. 
nucleotides on intestinal morphology and function, intestinal microflora, immune function as well as on growth performance are described with special focus on pigs, but, where applicable, data from human subjects and rodents are also included. Special attention is given to data describing the potential role of dietary nucleotides to improve piglets' health and development.

\section{Biochemical and functional characteristics of nucleotides}

Nucleotides are low-molecular-weight intracellular compounds that participate in numerous biochemical processes. They are composed of a nitrogenous base (pyrimidine or purine) linked to a pentose (ribose or deoxyribose) sugar ( = nucleoside) to which one, two or three phosphate groups are attached. The pyrimidines comprise cytosine (C), uridine (U) or thymine (T), as well as orotic acid, which is present in the milk of ruminants ${ }^{(19)}$, and which is produced as an intermediate product during the synthesis of uridine $5^{\prime}$-monophosphate (UMP). The purines comprise adenine (A), guanine (G) and hypoxanthine (I). The prefix $d$ is added when the sugar of the nucleotide consists of deoxyribose. The capital letters MP, DP and TP indicate mono-, di- and tri-phosphate esters, respectively $^{(8)}$. The purine and pyrimidine bases are hydrophobic and relatively insoluble in water at the near-neutral $\mathrm{pH}$ of the cell. At acid or alkaline $\mathrm{pH}$, the bases become charged and their solubility in water increases ${ }^{(20)}$. Nucleotides and nucleic acids are constantly being formed and degraded in all tissues, especially in tissues with a rapid turnover rate such as cells in the immune system, intestinal mucosa, skin, and progenitors of leucocytes or erythrocytes $^{(7)}$. For example, according to an in vitro study on intestinal explants from suckling piglets, the jejunum of piglets at weaning is able to hydrolyse RNA and free nucleotides to nucleosides, which, except for cytidine, are then efficiently taken up by the small intestine ${ }^{(21)}$. Generally, there are three potential sources of nucleotides: de novo synthesis, salvage pathways and the diet ${ }^{(8,22)}$. The de novo synthesis of nucleotides is a metabolically costly process requiring substantial amounts of energy in the form of $\mathrm{ATP}^{(9)}$. Within the de novo pathways in mammalian cells, the pyrimidine ring can be synthesised from aspartate, glutamine and $\mathrm{CO}_{2}$ whereas the purine ring can be formed from glycine, aspartate, glutamine, tetrahydrofolate derivates and $\mathrm{CO}_{2}{ }^{(23)}$. Another mechanism for maintaining the cellular nucleotide pools is the salvage pathway. Under fed conditions, this pathway recycles $90 \%$ or more of the purine bases. Thus, it is suggested that the salvage pathway is dependent on the availability of free purine and pyrimidine bases $^{(7)}$. This pathway requires less energy than the reactions needed for the de novo synthesis of nucleotides and is characterised by linkage of a ribose phosphate moiety to free bases formed by hydrolytic degradation of nucleic acid and nucleotides ${ }^{(8)}$. Also, some tissues have limited capacity for the de novo synthesis of nucleotides, thus requiring exogenously supplied bases that can be utilised by the salvage pathway $^{(24-26)}$. For example, the intestinal mucosa, the haematopoietic cells of the bone marrow, leucocytes, erythrocytes and lymphocytes are incapable of de novo synthesis ${ }^{(27)}$, and thus utilise the salvage pathway, suggesting that an exogenous supply of nucleotides via the diet might be important for these cells ${ }^{(8)}$.

The absorption, transport and use of exogenous nucleotides and nucleosides are complex processes, which have mainly been investigated in vitro by using mucosal exposures of the ileum and ex vivo by everted gut sacs of rabbits and rats ${ }^{(28,29)}$ or in cultured cell lines ${ }^{(30,31)}$ Under physiological conditions, nucleotides have a limited capacity to pass through cell membranes ${ }^{(27)}$. This may be due to the absence of a nucleotide transport system. Nucleotides also have a high negatively charged phosphate group that prevents them from being absorbed ${ }^{(27)}$. Except for small amounts, dietary nucleotides need to be enzymically hydrolysed before absorption, because only nucleosides and bases can be absorbed in the small intestine ${ }^{(32)}$. Endonucleases, phosphodiesterases, and nucleoside phosphorylases are the major enzymes involved in this transport process (Fig. 1). They originate from the brush-border epithelium ${ }^{(33,34)}$, $\operatorname{pancreas}^{(35)}$ and bile ${ }^{(36)}$ The duodenum has the most developed absorptive capacity for nucleosides ${ }^{(37)}$. Differences in the efficiency of uptake among nucleosides have been reported, with guanosine being taken up most rapidly ${ }^{(27)}$. More than $90 \%$ of dietary and endogenous nucleosides and bases are transported into the enterocytes ${ }^{(7,38)}$. Nucleoside transport into the enterocyte occurs by facilitated diffusion and by specific $\mathrm{Na}^{+}$-dependent carrier-mediated mechanisms ${ }^{(37)}$. Several enterocyte degradation products of dietary and endogenous nucleotides and nucleosides, mainly nitrogenous bases, such as adenine, cytosine, guanine, hypoxanthine, uracil or thymine, enter the hepatic portal vein. These molecules are carried to the hepatocytes for

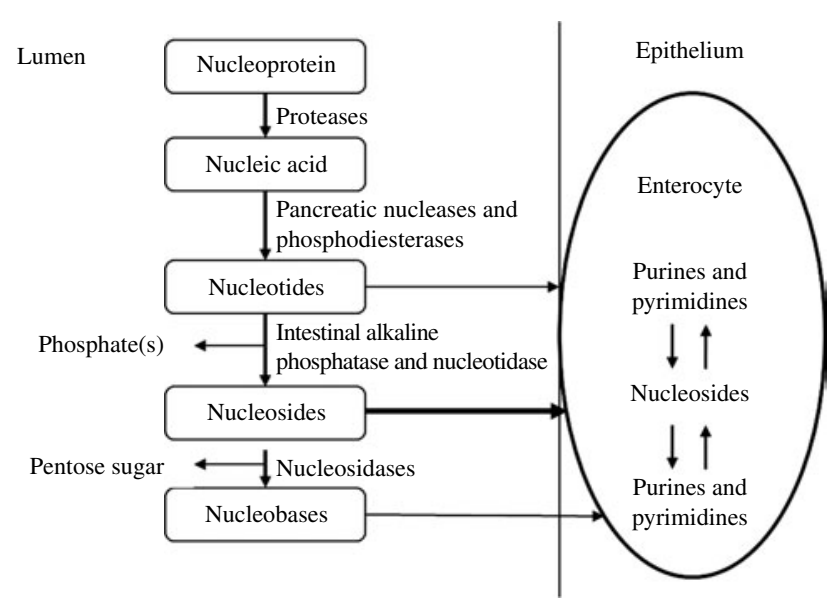

Fig. 1. Digestion and absorption of nucleoproteins and their related products (adapted from Quan \& Uauy ${ }^{(32)}$ ). 
further metabolism; thereafter, they are released from the liver into systemic circulation and enter muscle tissue. If these products are not re-utilised for nucleotide production or remain unabsorbed, the purine bases are catabolised into uric acid, whereas the pyrimidine bases are catabolised into $\beta$-alanine or $\beta$-aminoisobutyrate ${ }^{(23)}$. In mammals, except for primates, the catabolic product of purine, uric acid, is further catabolised into allantoin via the enzyme uricase to be excreted into the urine, whereas in avian species and primates, uric acid is excreted via the urine. The catabolic products of pyrimidine bases $(\beta$-alanine or $\beta$-aminoisobutyrate) are further metabolised into ammonia, carbon dioxide and acetyl coenzyme A.

Nucleotides play a key role in many biochemical processes, predominantly in cellular functions. They are precursors of nucleic acids, namely RNA and DNA, as they provide their monomeric units. The concentration of ribonucleotides is relatively constant in all cells, whereas the concentration of deoxyribonucleotides varies during the cell cycle $^{(39)}$. Furthermore, nucleotides may influence the cell cycle, for example, their withdrawal leads to the arrest of T-cells in the G-phase, preventing a response to various immunological signals that occur by transition to the S-phase ${ }^{(40)}$. Additionally, Paubert-Braquet et al. ${ }^{(41)}$ reported a decrease in phagocygotic activity, lymphokine production and/or inhibited lymphocyte maturation due to nucleotide removal. Furthermore, nucleotides, mainly the adenine nucleotides (ATP, ADP, AMP), are the most important molecules for the transfer of chemical energy from energy-yielding reactions to energy-requiring reactions ${ }^{(7,8)}$. Special forms of nucleotides activate as co-enzymes such as NAD, NADP, FAD and CoA, and play key roles as activated intermediates in the synthesis of lipids, carbohydrates and protein ${ }^{(7)}$. Nucleotides participate in biological regulation, particularly as cyclic AMP which is a second messenger used for intracellular signal transduction, such as transferring the action of hormones including glucagon and adrenaline, which cannot pass the cell membrane ${ }^{(42)}$. Further properties of cyclic AMP include the activation of protein kinase and regulating the effects of adrenaline and glucagon ${ }^{(43)}$. It also serves as a regulator of the passage of $\mathrm{Ca}^{2+}$ through ion channels ${ }^{(42)}$.

Besides their role in biochemical processes, nucleotides are eventually involved in biological reactions as well. Several in vivo studies suggest that dietary nucleotides may promote the development of the gastrointestinal ultrastructure $^{(17)}$, modulate the intestinal microbiota ${ }^{(16)}$ and have influences on immune function ${ }^{(44)}$. Although nucleotides are synthesised endogenously, it has been suggested that dietary supplementation with nucleotides may exert beneficial effects on small-intestinal growth and development, lipid metabolism and hepatic function (for a review, see Carver \& Walker $\left.{ }^{(9)}\right)$. Conditions under which nucleotides may become essential include certain disease states, periods of limited nutrient intake or rapid growth, and the presence of regulatory or developmental factors which may interfere with full expression of the endogenous synthetic capacity ${ }^{(7)}$. Under such conditions, dietary nucleotides may spare the cost of de novo synthesis and/or the salvage pathway, and thus may help to optimise the function of tissues requiring high concentrations of nucleotides (for example, intestinal mucosa). Furthermore, there is evidence that some cells, for example, erythrocytes, possess no or limited capacity for the de novo synthesis of nucleotides ${ }^{(9)}$. Additionally, the intestinal mucosa, as well as the haematopoietic cells of the bone marrow, for example, leucocyte proliferation, preferentially utilise preformed pyrimidine and purine bases ${ }^{(26)}$. These cells require exogenously supplied nucleotides that can be utilised via the salvage pathway rather than forming bases by de novo synthesis. For these cells, an exogenous supply of nucleotides may be essential for optimal function. There is sufficient de novo synthesis of purines and pyrimidines by the liver to meet its own requirements and the liver delivers bases to other tissues, for example, the intestine with high demands due to rapid turnover rates ${ }^{(26)}$. The allocation of purines and pyrimidines via de novo synthesis in the liver is linked to high energy expenditure. In the absence of dietary nucleotides, the de novo pathway for purine and pyrimidine synthesis is activated ${ }^{(26)}$. However, supplementing nucleotides may suppress the metabolic costly de novo synthesis, thereby activating the salvage pathway ${ }^{(24,25,45)}$. Thus, the term 'semi-essential nutrient' has been introduced to describe the role of dietary nucleotides in nutrition of newborn, adult or ill mammals when endogenous supply is insufficient for normal body function, even though their absence from the diet does not necessarily lead to classical clinical aetiopathology ${ }^{(46)}$.

\section{Contents of nucleotides in milk and other food and feed ingredients}

Colostrum and milk are the only nutrient supply in early life, and provide young animals with a source of nourishment which is ideally adapted to species-specific digestive and metabolic requirements at every stage of early life. Protection of the young animal against microbes is ensured via the intake of maternal immunoglobulins, lactoferrin, lysozymes, lactoperoxidase and oligosaccharides as well as leucocytes present in colostrum and milk (for a review, see $\left.\mathrm{Xu}^{(47)}\right)$. Furthermore, milk lipids have the potential to suppress inflammatory reactions in the piglet's gastrointestinal tract due to their antiviral, antibacterial and antiprotozoal activity ${ }^{(48)}$. Colostrum and milk assure sufficient supply with enzymes needed for digestion due to low production rates of endogenous enzymes in early life ${ }^{(49)}$. Furthermore, gastrointestinal functions may be promoted by the presence of bioactive components, for example, polyamines ${ }^{(50)}$, hormones and growth factors ${ }^{(47)}$, as well as nucleotides ${ }^{(51)}$ that have the potential to stimulate cell division and differentiation in the small intestine, by, for example, increased mitosis rates and lower 
Table 1. Comparison of the nucleotide composition ( $\mu \mathrm{mol} / 100 \mathrm{ml}$ ) of colostrum and milk from different species (adapted from Gil \& Sanchez-Medina ${ }^{(122)}$ )

\begin{tabular}{|c|c|c|c|c|c|c|c|c|}
\hline \multirow[b]{2}{*}{ Day of lactation... } & \multicolumn{2}{|c|}{ Human* } & \multicolumn{2}{|c|}{ Sow† } & \multicolumn{2}{|c|}{ Sheept } & \multicolumn{2}{|c|}{ Goat† } \\
\hline & 2 & 30 & 1 & 22 & 2 & 60 & 1 & 60 \\
\hline AMP & 3 & 2 & 9 & 6 & 30 & 9 & 5 & 7 \\
\hline CMP & 6 & 2 & 14 & 6 & 33 & 9 & 7 & 5 \\
\hline GMP & 4 & 3 & 8 & 4 & 4 & $\mathrm{Nd}$ & $\mathrm{Nd}$ & $\mathrm{Nd}$ \\
\hline IMP & - & - & - & - & - & - & - & - \\
\hline UMP & 2 & 1 & 103 & 12 & 113 & 25 & 54 & 15 \\
\hline Orotic acid & $\mathrm{Nd}$ & $\mathrm{Nd}$ & $\mathrm{Nd}$ & $\mathrm{Nd}$ & 4 & 4 & 8 & 12 \\
\hline
\end{tabular}

AMP, adenosine $5^{\prime}$-monophosphate; CMP, cytosine $5^{\prime}$-monophosphate; GMP, guanosine $5^{\prime}$-monophosphate; Nd, not detected; IMP, inosine $5^{\prime}$-monophosphate; -, not analysed; UMP, uridine $5^{\prime}$-monophosphate.

*Analysed with HPLC.

† Analysed with enzymic methods.

apoptosis rates ${ }^{(11)}$. A higher production rate of digestive enzymes in the epithelial cells may occur, thereby leading to an increased digestive and absorptive capacity of the intestine. Furthermore, according to Hartmann \& Holmes ${ }^{(49)}$, nucleotides present in sows' colostrum and milk belong to biologically active compounds that have the potential to influence the behaviour of piglets such as stimulating voluntary feed intake ${ }^{(52-55)}$

The nucleotide concentration in milk of mammals is species-specific and the concentration of most nucleotides changes during the lactation period (Table 1). When comparing colostrum and milk of different species, colostrum shows generally higher amounts of nucleotides, but there are species-specific differences in composition. For example, orotic acid, an intermediate product of UMP synthesis, is present in the colostrum and milk of ruminants but not of single-stomached animals (Table 1) ${ }^{(19)}$.

The composition of sows' milk, in terms of total milk solids, crude protein $(\mathrm{N} \times 6.38)$ and $5^{\prime}$-monophosphate nucleotide contents, during lactation is shown in Table 2. High concentrations of total milk solids, crude protein and UMP can be found at day 0 of lactation, followed by declining levels during the first week of lactation, while contents of AMP and GMP increase. From day 14 of lactation, the content of total milk solids, crude protein and all nucleotides decreases compared with the first $7 \mathrm{~d}$ of lactation. After day 21 of lactation, UMP $(122.8 \mu \mathrm{mol} /$ $100 \mathrm{ml}$ ) dominates in sows' milk, whereas concentrations of GMP, AMP, cytosine $5^{\prime}$-monophosphate (CMP) and inosine $5^{\prime}$-monophosphate (IMP) average $6 \cdot 0,4 \cdot 3,2 \cdot 3$ and $<1.0 \mu \mathrm{mol} / 100 \mathrm{ml}$, respectively.

Nucleotides, particularly IMP, are mainly found in protein-rich food ingredients ${ }^{(5)}$, such as organ meats, poultry and seafood ${ }^{(5,39,56)}$. Yeast protein sources, such as baker's or brewer's yeast and yeast extract, are ingredients that also show a relatively high concentration of nucleotides $^{(57-59)}$. However, feed ingredients commonly used in animal nutrition are not routinely analysed for nucleotide content, resulting in limited information for many feedstuffs. The few data that are available show that, in comparison with colostrum and milk, there are rather low concentrations of individual nucleotides in feedstuffs such as barley, soya protein concentrate and soyabean meal (Table 3$)^{(60)}$. For example, the concentration of UMP in milk amounts to $122.8 \mu \mathrm{mol} / 100 \mathrm{ml}$ on lactation day 21 (Table 2), whereas barley contains no UMP and soyabean meal only $0.9 \mathrm{mg} / 100 \mathrm{~g}$ (Table 3). Furthermore, AMP, CMP, GMP and IMP concentrations vary in feedstuffs between non-detectable levels (for example, GMP content of casein) and $1.9 \mathrm{mg} / 100 \mathrm{~g}$ (AMP content of dried whey). Higher concentrations can be found for AMP in spraydried erythrocytes $(4.4 \mathrm{mg} / 100 \mathrm{~g})$, for CMP in dried whey $(27.0 \mathrm{mg} / 100 \mathrm{~g})$ and in fish meal $(2.6 \mathrm{mg} / 100 \mathrm{~g})$ as well as for IMP in fish meal $(3.5 \mathrm{mg} / 100 \mathrm{~g})$.

\section{Biological effects of dietary nucleotides}

\section{Physiological, morphological and metabolic effects}

Hepatic morphology and function. Several studies with rodents and cats are available focusing on potential effects of supplemental dietary nucleotides and/or nucleosides on blood parameters ${ }^{(14)}$, on hepatic blood flow ${ }^{(61)}$ and on liver morphology ${ }^{(62)}$. Novak et al. ${ }^{(14)}$ reported increased hepatic cholesterol and lipid $\mathrm{P}$ concentration as well as

Table 2. Concentration of total milk solids, crude protein (nitrogen $\times 6 \cdot 38$ ) and $5^{\prime}$-monophosphate nucleotides in colostrum and milk from sows at different lactation stages (adapted from Mateo et al. ${ }^{(6)}$ )

(Mean values with their pooled standard errors)

\begin{tabular}{|c|c|c|c|c|c|c|c|}
\hline \multirow[b]{2}{*}{ Item } & \multicolumn{6}{|c|}{ Day of lactation } & \multirow[b]{2}{*}{ SEM } \\
\hline & 0 & 3 & 7 & 14 & 21 & 28 & \\
\hline Total milk solids (\%) & $26 \cdot 7$ & $23 \cdot 4$ & $19 \cdot 4$ & $18 \cdot 2$ & $18 \cdot 8$ & $19 \cdot 2$ & 0.71 \\
\hline Crude protein (\%) & $16 \cdot 6$ & $7 \cdot 8$ & $6 \cdot 2$ & 5.5 & $5 \cdot 7$ & $6 \cdot 3$ & 0.41 \\
\hline \multicolumn{8}{|c|}{$5^{\prime}$-Monophosphate nucleotides $(\mu \mathrm{mol} / 100 \mathrm{ml})$} \\
\hline AMP & 4.0 & $11 \cdot 3$ & $12 \cdot 8$ & $6 \cdot 8$ & $4 \cdot 3$ & 3.0 & $2 \cdot 19$ \\
\hline CMP & 1.5 & $7 \cdot 1$ & $7 \cdot 1$ & 3.5 & $2 \cdot 3$ & 0.9 & 0.98 \\
\hline GMP & $5 \cdot 4$ & $14 \cdot 7$ & 14.0 & $10 \cdot 2$ & 6.0 & $7 \cdot 1$ & 1.41 \\
\hline IMP & $1 \cdot 1$ & $1 \cdot 8$ & 2.6 & 1.4 & 0.9 & 0.4 & 0.38 \\
\hline UMP & $555 \cdot 6$ & $305 \cdot 6$ & $263 \cdot 1$ & 144.0 & $122 \cdot 8$ & 104.0 & 27.05 \\
\hline
\end{tabular}

AMP, adenosine 5'-monophosphate; CMP, cytosine 5'-monophosphate; GMP, guanosine 5'-monophosphate; IMP, inosine 5'-monophosphate; UMP, uridine $5^{\prime}$-monophosphate. 
Table 3. Nucleotide concentration ( $\mathrm{mg} / 100 \mathrm{~g}$, as is) in commonly used feed ingredients (adapted from Mateo \& Stein ${ }^{(60)}$ )

\begin{tabular}{lccccc}
\hline Ingredient & 5'-CMP & $5^{\prime}$-AMP & 5'-GMP & 5'-UMP & 5'-IMP \\
\hline Barley & 0.2 & 0.1 & 0.1 & 0.0 & 0.1 \\
Casein & 0.1 & 0.0 & 0.0 & 0.0 & 0.0 \\
Maize & 0.3 & 0.2 & 0.3 & 0.0 & 0.1 \\
Fish meal & 2.6 & 1.1 & 0.2 & 0.1 & 3.5 \\
Naked oats & 0.3 & 0.3 & 0.3 & 0.1 & 0.1 \\
Plasma protein, spray dried & 0.2 & 0.2 & 0.2 & 0.0 & 0.1 \\
Erythrocytes, spray dried & 0.0 & 4.4 & 0.3 & 0.2 & 0.6 \\
Soya protein concentrate & 0.0 & 0.1 & 0.2 & 0.0 & 0.1 \\
Soyabean meal, 44\% & 1.6 & 0.8 & 0.3 & 0.9 & 0.2 \\
Whey, dried & 27.0 & 1.9 & 0.0 & 0.1 & 0.4 \\
\hline
\end{tabular}

5'-CMP, cytosine 5'-monophosphate; 5'-AMP, adenosine 5'-monophosphate; $5^{\prime}$-GMP, guanosine

$5^{\prime}$-monophosphate; $5^{\prime}$-UMP, uridine $5^{\prime}$-monophosphate; $5^{\prime}$-IMP, inosine $5^{\prime}$-monophosphate.

decreased liver weight and glycogen content when feeding nucleotide-free diets to weanling mice, in comparison with mice receiving nucleotide-enriched diets. They concluded that dietary nucleotide supplementation in general may affect hepatic growth and composition in weanling mice. However, these differences were more pronounced if the diet was supplemented with AMP alone rather than with a mixture of different nucleotides including AMP, CMP, GMP, IMP and UMP. Furthermore, the effects of added extracellular nucleotides or nucleosides, and their mixture, on primary monolayer cultures of normal hepatocytes and cultures of hepatoma cells (AH130) on DNA and RNA syntheses was studied by Ohyanagi et al. ${ }^{(63)}$, who found that a mixture of nucleotides and nucleosides at a concentration of $335 \mathrm{mg} / \mathrm{dl}(3350 \mathrm{mg} / \mathrm{l})$ inhibited the syntheses of DNA and RNA by hepatocytes and hepatoma cells. Also, they found that excessive concentrations of nucleotide and nucleoside mixtures reduce the proliferation of both hepatocytes and hepatoma cells. However, Ohyanagi et $a l .{ }^{(63)}$ assumed that the addition of mixtures of nucleosides and nucleotides at lower levels $(33.5 \mathrm{mg} / \mathrm{dl} ; 335 \mathrm{mg} / \mathrm{l})$ would enhance the growth of hepatocytes, particularly during liver regeneration, but on the other hand they may also enhance the proliferation of tumour cells in the liver. These findings were confirmed in studies with rats $^{(62)}$ and rabbits ${ }^{(64)}$ that were diagnosed with liver damage after hepatectomy. For example, rats receiving total parenteral nutrition with a nucleotide and nucleoside mixture after $70 \%$ hepatectomy showed earlier restoration of their $\mathrm{N}$ balance when compared with animals that were not supplied with this mixture ${ }^{(65)}$. Further studies by Ogoshi et al. ${ }^{(62)}$ showed that parenteral nutrition based on a balanced mixture of nucleosides and nucleotides at a physiological level may improve hepatic function in rats and promote earlier restoration of $\mathrm{N}$ balance following liver injury. These findings were confirmed in experiments with hepatectomised rabbits which showed an enhanced mitochondrial phosphorylative activity in the remnant liver, when fed a nucleoside-nucleotide mixture ${ }^{(64)}$. Similarly, in hepatectomised rabbits, a continuous intravenous infusion of a nucleoside-nucleotide mixture led to an increased mitochondrial phosphorylative activity and elevated DNA content of the remnant liver ${ }^{(66)}$.

Lipid metabolism. A study with human infants revealed no differences in HDL-cholesterol levels when a group receiving a nucleotide-enriched diet was compared with a breast-fed and a control group (milk formula-fed without nucleotide supplementation) ${ }^{(67)}$. However, the authors found lower VLDL-cholesterol concentrations and increased HDL concentrations in the nucleotide-fed and breast-fed groups than in the control group. These findings suggest that nucleotides may play a role in lipoprotein synthesis ${ }^{(68)}$. Moreover, nucleotides eventually interfere with the formation of LDL-cholesterol by affecting apoprotein synthesis $^{(7)}$. Similarly, orotic acid, an intermediate product of UMP synthesis, may induce fatty liver in rats by blocking VLDL secretion due to an inhibition of hepatic apo B synthesis ${ }^{(69-71)}$.

Feeding a nucleotide-supplemented formula to rats has been associated with higher plasma levels of long-chain PUFA $^{(72,73)}$ and, according to the results of a study by Jimenez et al. ${ }^{(74)}$, supplementation of nucleotides (AMP, CMP, GMP, IMP, UMP) to diets of rats enhanced the concentrations (mainly of the $n-6$ series) of long-chain PUFA of erythrocyte membranes compared with the control group. The authors, therefore, suggest that dietary nucleotides may have the potential to modify the conversion of essential fatty acids into their long-chain derivates. Ramírez et $a l{ }^{(72)}$ obtained an increase in the prostaglandin thromboxane $\left(\mathrm{TXA}_{2}\right)$, and a trend towards higher prostaglandin 6-keto-PGF ${ }_{1 \alpha}$ levels when a semi-purified standard diet for weanling rats was supplemented with $50 \mathrm{mg} / 100 \mathrm{~g}$ each of the nucleotides AMP, CMP, GMP, IMP and UMP. These results coincided with an increased plasma concentration of arachidonic acid, a precursor for the production of the eicosanoids $\mathrm{TXA}_{2}$ and $\mathrm{PGI}_{2}$. The authors concluded that dietary purines and pyrimidines positively affect PUFA composition and therefore eicosanoid synthesis.

Dietary nucleotides may promote faster recoveries from nodular cirrhosis of the liver artificially induced by thioacetamide. For example, the addition of dietary nucleotides (AMP, CMP, GMP, IMP, UMP) following thioacetamide 
administration induced a decrease in the percentage area of fibrous septae in the liver of rats ${ }^{(75)}$. Furthermore, the authors found a reduced total area of fibrosis in animals with liver cirrhosis after feeding the nucleotide-enriched diet for 2 weeks. In a study by Fontana et al. ${ }^{(76)}$, rats with experimental cirrhosis induced by carbon tetrachloride $\left(\mathrm{CCl}_{4}\right)$ showed lower saturated (mainly stearic acid), monounsaturated and n-6 long-chain PUFA (mainly arachidonic acid) concentrations as well as a reduced unsaturation index in plasma. Administration of a diet supplemented with nucleotides (AMP, GMP, CMP, IMP, $\mathrm{UMP}$ ) to $\mathrm{CCl}_{4}$-treated rats led to a microsomal fatty acid profile closer to the group that received the semi-purified diet without $\mathrm{CCl}_{4}$ treatment. Furthermore, a high level of ( $n-6)$ PUFA, particularly arachidonic acid, was observed in liver microsomal phospholipids of the rats fed the nucleotide-supplemented diet. The authors concluded that nucleotides are important for the recovery of liver function following hepatic damage.

Intestinal morphology and function. In the intestine, exogenous nucleotides are important for rapidly dividing mucosal cells, due to absent ${ }^{(24)}$ or limited ${ }^{(25)}$ de novo nucleotide synthesis. Some studies in single-stomached animals have focused on the effect of supplemental commercial products containing pure nucleotides or nucleotide-enriched diets on the intestinal ultrastructure $^{(15)}$, on intestinal cell proliferation ${ }^{(77)}$, but also on intestinal enzyme activities ${ }^{(78)}$, and on recovery from diarrhoea $^{(79)}$. For example, intestinal cell proliferation could be increased by adding a nucleoside-nucleotide mixture to a diet for rats $^{(80)}$ or by supplementing pigs' diets with a commercial product containing nucleotides ${ }^{(11)}$. Under in vitro conditions, exogenous nucleotides (AMP, CMP, GMP, IMP, UMP) did not affect human colon tumour cell line (Caco-2 cell) proliferation, although significantly higher maltase and sucrase activities could be found ${ }^{(77)}$. In the same study, however, an enhancement of cell proliferation and maltase activity could be observed in a normal small-intestinal crypt cell line (intestinal epithelial cell-6) of rats. Under in vivo conditions with earlyweaned rats, these authors reported higher small-intestinal sucrase activities, and they concluded that dietary nucleotides may enhance enterocyte proliferation and/or maturation both under in vitro and in vivo conditions. However, N Sauer, M Eklund, S Roth and R Mosethin (unpublished results) could not confirm these findings in a study with piglets fed a commercial product containing nucleotides, since $\alpha$-amylase, maltase, lactase and leucine aminopeptidase activities in ileal digesta on days 13 and 20 after weaning were not affected. Furthermore, Lee et $a l .{ }^{(44)}$ found an increase in gastric pepsin and jejunal alkaline phosphatase activity, associated with a decrease in ileal aminopeptidase, sucrase and maltase activity, following the supplementation of the diet for weaned pigs with $0 \cdot 1 \%$ of a commercially available nucleotide product. Moreover, a study with rats revealed that withdrawal of dietary nucleotides led to a decrease in the content and specific activity of alkaline phosphatase, leucine aminopeptidase, maltase, sucrase and lactase in the villous tip $^{(78)}$. These authors hypothesised that dietary nucleotides may affect the maturation status of the small-intestinal epithelium, since the aforementioned enzymes are maturation markers of intestinal cells.

The addition of a commercial nucleotide-containing product to the diet of weanling piglets may influence intestinal morphology, as indicated by a higher mitosis and lower apoptosis rate ${ }^{(11)}$ and a decrease in villous atrophy after weaning ${ }^{(15)}$. For example, Shen et al. ${ }^{(81)}$ found a higher villous height and villous height:crypt depth ratio in a yeast-supplemented group compared with an unsupplemented group. Furthermore, Godlewski et al. ${ }^{(82)}$ showed an increase in the rate of apoptosis as well as lower DNA damage and lower mitosis apoptosis index in pigs fed a diet supplemented with a commercial product containing nucleotides in comparison with the unsupplemented control treatment. Similarly, adding nucleosides, the degradation products of nucleotides, to the diets of rats enhanced mucosal protein and intestinal DNA content ${ }^{(17)}$. On the other hand, studies by van der Peet-Schwering et al. ${ }^{(55)}$ did not indicate an increased villous length and crypt depth when adding a commercial product based on yeast culture to diets for piglets.

There are further contradictory results with regard to possible effects of dietary nucleotides on nutrient digestibilities. It can be speculated if these differences can be attributed to differences in origin and dietary level of nucleotides, to variations in the adaptation period of the administered nucleotides before the start of the experiment and/or to differences in the age of the experimental animals. For example, in a study by Kornegay et al. ${ }^{(83)}$ with piglets (aged 25-29d) there was no effect on apparent digestibilities of DM, N, neutral-detergent fibre and aciddetergent fibre, as well as on $\mathrm{P}$, when $0.75 \%$ of a commercial product containing nucleotides was fed. Similarly, N Sauer, M Eklund, S Roth and R Mosethin (unpublished results) found no effects on ileal digestibilities of DM, crude protein, crude ash and crude fibre in piglets (aged 24-38d) fed a diet supplemented with 1000 parts per million of a commercial product containing nucleotides. However, Shen et al. ${ }^{(81)}$ reported higher apparent digestibilities of DM, crude protein and net energy in piglets (aged 21-42d) fed a diet supplemented with $5 \mathrm{~g} / \mathrm{kg}$ of a yeast culture product compared with the control group. On the other hand, van Heugten et al. ${ }^{(53)}$ observed lower digestibilities of DM, fat and net energy in the pre-starter phase, and also a decrease in DM, fat, $\mathrm{P}$ and net energy digestibility in the starter phase of piglets (aged 17-45d) which were fed a live yeast product $\left(1.6 \times 10^{7}\right.$ colonyforming units Saccharomyces cerevisiae/g feed) in comparison with the control treatment.

After recovery from diarrhoea, rats fed a nucleotideenriched diet showed an intestinal histology and ultrastructure close to those of the normal uninfected control 
group $^{(84)}$. The authors suggested that dietary nucleotides may be important nutrients for intestinal repair following infection. Accordingly, Nunez et al. ${ }^{(85)}$ reported in weanling rats faster intestinal recovery after chronic diarrhoea, as indicated by higher intestinal DNA contents and disaccharidase activities when adding nucleotides (AMP, CMP, GMP, IMP, UMP) to a basal diet with lactose as the main carbohydrate compared with a basal diet containing glucose polymers as the main dietary carbohydrate source. Additionally, Arnaud et al. ${ }^{(79)}$ reported that nucleotide supplementation (AMP, CMP, GMP, IMP, UMP) of diets of rats with lactose-induced diarrhoea resulted in faster recoveries for the nucleotide-supplemented group than for the control group. The authors concluded that dietary nucleotides are able to promote earlier restoration of the ileal mitochondrial function after chronic diarrhoea. With regard to weaning-associated diseases in pigs, few studies have been performed investigating the effect of supplemental nucleotides on the disposition to diarrhoea. MartinezPuig et al. ${ }^{(15)}$ observed faster recovery from diarrhoea when a commercial product containing nucleotides was included in a diet of weanling piglets. On the other hand, according to Bekaert et al. ${ }^{(86)}$, there was no effect on the incidence of diarrhoea in pigs fed a diet supplemented with a yeast culture (Saccharomyces cerevisiae).

With regard to the use of dietary nucleotides in weaned pigs, possible effects on Fe absorption might be of importance, as Fe is a mineral which frequently becomes deficient in swine diets (for a review, see National Research Council $^{(87)}$ ). The hepatic Fe stores of the newborn piglet combined with the low Fe concentration in sows' milk are not sufficient to meet the pig's Fe need for rapid growth and increase in blood volume ${ }^{(88)}$. Consequently, the use of exogenous sources of $\mathrm{Fe}$ to prevent $\mathrm{Fe}$ deficiency in neonatal pigs has been well documented $^{(89,90)}$. However, the bioavailability of Fe from different sources may vary considerably ${ }^{(91,92)}$, and, according to Rincker et $a l .{ }^{(88)}$, is not only dependent on the Fe status of the animal but also on dietary Fe as well as on various nutritional and non-nutritional substances within the diet. Dietary nucleotides, particularly the degradation product of IMP, inosine, might play a role in facilitating intestinal Fe absorption ${ }^{(93)}$. Cheney \& Finch $^{(93)}$ found an improved Fe absorption in rats following intravenous inosine administration. Furthermore, Faelli \& Esposito ${ }^{(94)}$ investigated the effect of inosine supplementation on Fe absorption in the everted gut of rats. The authors confirmed an increase in Fe absorption and suggested that nucleotides in milk may affect the gut microflora indirectly by increasing Fe absorption in the small intestine.

\section{Immunological effects}

Various studies have focused on the effect of supplemental dietary nucleotides on the immune function in human subjects $^{(95)}$ and pigs ${ }^{(96)}$; however, most studies have been performed in rodents ${ }^{(13)}$. For example, feeding nucleotide-supplemented diets to rodents has been associated with an increase in graft $v$. host disease mortality ${ }^{(97)}$, a rejection of allogenic grafts ${ }^{(98,99)}$ and a delayed cutaneous hypersensitivity ${ }^{(100)}$. However, other studies with rodents have revealed faster recovery of malnutrition- and starvation-induced immunosuppression $^{(101,102)}$, an increase in antigen-induced lymphoproliferation ${ }^{(102)}$ as well as higher natural killer cell activity and IL-2 production ${ }^{(103)}$. Additionally, resistance to a challenge with Candida albicans $^{(104)}$ and Staphylococcus aureus ${ }^{(105)}$ by activating humoral and cell-mediated immunity has been observed in mice fed diets enriched with nucleotides originating from yeast and RNA, respectively. The results of several studies pertaining to possible effects of dietary nucleotides on immune function in mice are summarised in Table 4.

Dietary nucleotides may also affect immune function in pigs. For example, Godlewski et al. ${ }^{(82)}$ observed higher autophagy capacity in the mid-jejunum of pigs fed a diet supplemented with a commercial nucleotide product compared with the control group. Additionally, Domeneghini et $a l .{ }^{(11)}$ reported differences in the growth and maturation of the intestinal mucosa by adding $0.05 \%$ nucleotides to a weanling piglet diet, especially as indicated by higher percentages of macrophages in the intestine and higher intra-epithelial lymphocytes. Due to close and intimate contact with the epithelial cells and the environment, higher numbers of intra-epithelial lymphocytes, components of the intra-epithelial defensive system, play an important role in mucosal immunity. They possess a number of pathogen-specific and non-specific functions enabling them to play a critical role in host defences at mucosal surfaces. For example, higher intra-epithelial lymphocytes have been shown to possess pathogen-specific cytotoxic T-cell activity ${ }^{(106)}$, and to be capable of mediating delayed-type hypersensitivity responses ${ }^{(107)}$. Moreover, they also secrete various cytokines such as interferon- $\gamma$, TNF- $\alpha$ and IL-2 ${ }^{(108,109)}$, which may play an important role in immune modulation at the mucosal surfaces. Furthermore, Lee et $a l^{(44)}$ demonstrated an immunomodulating effect as indicated by increased levels of plasma immunoglobulins (IgA, IgM) in weaned pigs when fed a commercial product containing nucleotides at $0.1 \%$. A study by Cameron et al. ${ }^{(96)}$ revealed that feeding nucleotides to early-weaned piglets may enhance T-cell functions in delayed hypersensitivity to antigenic challenge in the intestine and in vitro lymphocyte proliferation response to concanavalin $\mathrm{A}$, a mitogen which stimulates T-lymphocytes. The duration of the nucleotide supplementation seems to be critical for exhibiting effects on cell functions and cell proliferation, as the immuno-enhancing effects described above require at least 2 weeks of administration to the pigs ${ }^{(96)}$. However, a higher mitotic activity in the ileum could be shown when feeding a combination of $0.05 \%$ nucleotides and $0.5 \%$ glutamine. Thus, the inclusion of nucleotides and glutamine to a weanling 
Table 4. Effect of dietary nucleotides on immune functions in mice

\begin{tabular}{|c|c|c|c|}
\hline Response criteria & Amount added & Nucleotide source & Reference \\
\hline Resistance of microbial challenge $\uparrow$ & $0.25 \%$ & RNA & Fanslow et al. $(1988)^{(104)}$ \\
\hline Mortality $\downarrow$ & $0.06 \%$ & Adenine & \\
\hline Macrophage activity $\uparrow$ & $\begin{array}{l}0.06 \% \\
0.035 \%\end{array}$ & $\begin{array}{l}\text { Uracil } \\
\text { Cp }\end{array}$ & Carver et al. (1990) ${ }^{(103)}$ \\
\hline \multicolumn{4}{|l|}{ Natural killer cell activity $\uparrow$} \\
\hline \multicolumn{4}{|l|}{ Spleen weight $\uparrow$} \\
\hline $\begin{array}{l}\text { Reversal of immunosuppression after malnutrition } \uparrow \\
\text { Popliteal lymph node reactivity } \uparrow\end{array}$ & $0.25 \%$ & Yeast RNA & Pizzini et al. (1990) $)^{(101)}$ \\
\hline Neutrophil numbers following infection $\uparrow$ & $0.5 \%$ & $\mathrm{Cp}$ & Matsumoto et al. (1995) $)^{(123)}$ \\
\hline $\mathrm{IFN}-\gamma \uparrow$ & $3 \mathrm{~mol} / \mathrm{kg}$ & Single nucleosides; mixture & Yamauchi et al. (1996) $)^{(124)}$ \\
\hline \multicolumn{4}{|l|}{ Cutanous hypersensitivity retardation $\uparrow$} \\
\hline \multicolumn{4}{|l|}{ Cytokine secretion $\uparrow$} \\
\hline \multicolumn{4}{|l|}{ Lymphoproliferation $\uparrow$} \\
\hline $\lg E \downarrow$ & $1.62 \mathrm{~g} / \mathrm{kg}$ & CMP & Nagafuchi et al. (1997) $)^{(13)}$ \\
\hline Serum IgG1:IgG2a $\downarrow$ & $0.57 \mathrm{~g} / \mathrm{kg}$ & GMP & \\
\hline IL-4 $\downarrow$ & $1.10 \mathrm{~g} / \mathrm{kg}$ & IMP & \\
\hline $\mathrm{IFN}-\gamma \uparrow$ & $0.71 \mathrm{~g} / \mathrm{kg}$ & UMP & \\
\hline $\mathrm{TCR}_{\gamma} \delta^{+} \uparrow$ & $1.62 \mathrm{~g} / \mathrm{kg}$ & CMP & Nagafuchi et al. (2000) $)^{(125)}$ \\
\hline $\operatorname{TCR} \alpha \beta^{+} \downarrow$ & $0.57 \mathrm{~g} / \mathrm{kg}$ & GMP & \\
\hline \multirow[t]{2}{*}{$\mathrm{IL}-7 \uparrow$} & $1.10 \mathrm{~g} / \mathrm{kg}$ & IMP & \\
\hline & $0.71 \mathrm{~g} / \mathrm{kg}$ & UMP & \\
\hline IFN- $\gamma \uparrow$ & $1.62 \mathrm{~g} / \mathrm{kg}$ & CMP & Nagafuchi et al. (2000) $)^{(126)}$ \\
\hline $\mathrm{IL}-12 \uparrow$ & $0.57 \mathrm{~g} / \mathrm{kg}$ & GMP & \\
\hline \multirow[t]{2}{*}{$\operatorname{IgE} \downarrow$} & $1.10 \mathrm{~g} / \mathrm{kg}$ & IMP & \\
\hline & $0.71 \mathrm{~g} / \mathrm{kg}$ & UMP & \\
\hline TGF- $\beta \uparrow$ & $1.62 \mathrm{~g} / \mathrm{kg}$ & CMP & Nagafuchi et al. (2002) ${ }^{(127)}$ \\
\hline $\mathrm{IEL} \uparrow$ & $0.57 \mathrm{~g} / \mathrm{kg}$ & GMP & \\
\hline \multirow[t]{2}{*}{ IL-7 † } & $1.10 \mathrm{~g} / \mathrm{kg}$ & IMP & \\
\hline & $0.71 \mathrm{~g} / \mathrm{kg}$ & UMP & \\
\hline CD22 $\uparrow$ & $\mathrm{Nr}$ & $\mathrm{Nr}$ & Manzano et al. $(2004)^{(128)}$ \\
\hline \multirow{2}{*}{\multicolumn{4}{|c|}{$\begin{array}{l}\text { CD5 } \uparrow \\
\text { Lymphocyte maturation } \uparrow\end{array}$}} \\
\hline & & & \\
\hline Comet cells $\uparrow$ & $0.25 \%$ & AMP, CMP, GMP, UMP & Wang et al. (2008) $)^{(129)}$ \\
\hline \multicolumn{4}{|l|}{ Comet trail size $\uparrow$} \\
\hline Thymus and spleen weights $\uparrow$ & & & \\
\hline
\end{tabular}

piglet diet appears to have a positive effect on the maturation of the ileal mucosa by supporting the development of lymphocytes and thereby providing an immunereactive intestine. Furthermore, Salobir et al. ${ }^{(110)}$ found, upon feeding a diet supplemented with different levels of PUFA to growing pigs, that a commercial product of nucleotides may effectively eliminate the genotoxic effect of high PUFA intakes on blood lymphocytes, thus demonstrating new evidence for the immuno-nutritive potential of dietary nucleotides.

\section{Microbial effects}

Few in vitro studies have been performed pertaining to possible effects of supplemental nucleotides or nucleosides on the growth of single bacterial strains; however, results are rather controversial. For example, an in vitro study of Tanaka \& Mutai ${ }^{(111)}$ showed that nucleosides (adenine, guanine, xanthine, uracil) in combination with pyruvic acid and riboflavin in a minimal culture medium promote the growth of bifidobacteria. Accordingly, Uauy ${ }^{(7)}$ summarised that $\mathrm{Gil}^{(112)}$ obtained a slight but significant stimulation of bifidobacterial in vitro growth upon the addition of single nucleotides (AMP, CMP, GMP, IMP, UMP) to a minimal medium. This stimulatory effect was even more pronounced when a mixture of these monophosphate nucleotides was included in the assay. On the other hand, Sauer et al. ${ }^{(113)}$ obtained no differences in the growth responses of Lactobacillus reuteri (strain DSM 20 016), L. amylovorus (DSM 20 513), Enterococcus faecium (DSM 2146) and E. faecalis (DSM 6134) when adding single nucleotides (AMP, CMP, GMP, IMP, UMP) to a minimal medium. However, the authors found diverse growth responses for different Escherichia coli strains (E. coli DSM 2840, E. coli PS 37, E. coli PS 79) upon the addition of single nucleotides to a minimal medium, depending on the type of nucleotide as well as on the concentration used, but also on the specific bacterial strain tested. These results suggest that bacteria might be able to use nucleosides and/or nucleotides for their proliferation, although this has to be confirmed by further in vitro studies by expanding the range of bacterial strains under investigation.

Roselli et al..$^{(114)}$ evaluated the potential of several natural substances (for example, yeast extract) to protect against enterotoxigenic Escherichia coli (ETEC) 
K88-induced membrane damage by using intestinal pig epithelial cells-1. The authors showed that a commercial product containing nucleotides could protect the cells against an increase in membrane permeability caused by enterotoxigenic Escherichia coli. Additionally, results from an in vivo study with human subjects suggest that dietary nucleotides may modify the composition of the intestinal microflora by promoting beneficial bacteria including bifidobacteria and lactobacilli ${ }^{(16)}$. Young infants fed a formula containing dietary nucleotides (AMP, CMP, GMP, IMP, UMP) had higher percentages of faecal bifidobacteria and lactobacilli and lower percentages of Gramnegative enterobacteria than formula-fed infants without supplementation $^{(16)}$. High numbers of intestinal bifidobacteria and lactobacilli are required, in particular around the time of weaning during the transition from liquid to solid feeding. For example, bifidobacteria may lower the $\mathrm{pH}$ of the colonic content due to their capacity to hydrolyse sugars to lactic acid which, in turn, may suppress the proliferation of acid-susceptible pathogenic bacteria. Bifidobacteria also may inhibit the growth of enterobacteria responsible for diarrhoeal diseases (for a review, see Braun $^{(115)}$ ). However, only few studies are available pertaining to the effect of dietary nucleotides on the composition and activity of the intestinal microflora of young pigs. For example, Andrés-Elias et al. ${ }^{(4)}$ concluded that nucleotides appear to modulate the intestinal ecology in weanling piglets by stabilising the microbiota in the ileum, when testing nucleotides (commercially available product) as possible alternatives to antimicrobial growth promoters. However, Mathew et al. ${ }^{(52)}$ could not show any differences in total ileal numbers of Escherichia coli, lactobacilli and streptococci as well as in microbial metabolites (SCFA composition), when feeding yeast cultures (Saccharomyces cerevisiae) to weanling piglets. Similarly, N Sauer, M Eklund, S Roth and R Mosethin (unpublished results) failed to observe a response in ileal counts of lactobacilli, bifidobacteria, enterococci and eubacteria as well as in the level of microbial metabolites, including SCFA and lactic acids, when feeding a diet to weaning piglets supplemented with a commercial product containing nucleotides. Also, no changes in the PCR-denaturing gradient gel electrophoresis fingerprint analysis of total bacterial community profile could be shown when adding nucleotides (yeast culture) to diets of pigs ${ }^{(55)}$. Results of studies pertaining to the effect of nucleotides, given either as single nucleotides or originating from yeast products, on the composition and activity of the intestinal microbiota of humans and pigs are still equivocal.

\section{Zootechnical effects}

Several studies have been conducted focusing on the growth-promoting effect of dietary nucleotides, supplemented as yeast products to pig diets (Table 5). In several studies dietary nucleotides as a yeast product were added to the diets of pigs of different ages but failed to improve growth performance $e^{(4,11,53,55,83,86,96,116,117)}$. Similarly, a study by Sijben et al. ${ }^{(118)}$ showed that dietary yeast nucleotides (Saccharomyces cerevisiae) did not affect energy intake, heat production and energy retention of barrows. On the other hand, supplementation of yeast products to diets of piglets resulted in similar improvements in growth performance as compared with antimicrobial growth promoters ${ }^{(55,81)}$. Similarly, Mathew et al. ${ }^{(52)}$ observed a trend towards an increased growth rate in pigs fed a diet supplemented with live yeast (Saccharomyces cerevisiae) from weaning until age $41 \mathrm{~d}$. Furthermore, the addition of nucleotide products alone or in combination with glutamine to diets of weaning piglets has revealed contradictory results. Domeneghini et al. ${ }^{(11)}$ observed no difference in body weight and feed intake, whereas in a study by $\mathrm{Yi}$ et $a l^{(119)}$ a combination of nucleotides (RNA) and glutamine improved average daily gain and feed intake. Further studies investigated sows' and piglets' performance upon supplementation of sows' diets with yeast products. Jurgens et al. ${ }^{(120)}$ and Moore et $a l{ }^{(121)}$ found higher growth performance in piglets when adding live yeast (Saccharomyces cerevisiae) and a commercial product containing Saccharomyces cerevisiae, respectively, to sows' diets.

\section{Conclusions}

There is increasing evidence that dietary nucleotides may affect different aspects of body function and health in single-stomached animals, including intestinal morphology and function, immune response, the composition of the intestinal microbiota, liver function and morphology as well as growth performance. Although nucleotides can be synthesised de novo, several tissues, including those with a rapid turnover rate such as the intestine, may benefit from an exogenous supply to decrease energy expenditures. In times of disease states, periods of limited nutrient intake or rapid growth, such as the weaning period, nucleotides can become semi-essential nutrients, as in general nucleotides are present at very low levels in animal diets. Furthermore, due to the ban of in-feed antibiotics, efficient and feasible alternatives have gained increasing attention to improve the health of animals, to increase the potential to withstand infectious diseases and to secure growth performance. For dietary nucleotides, beneficial effects have been proven for a faster intestinal recovery after challenge with, for example, diarrhoea, and also for a faster immune response in several disease situations, for example, malnutrition. A decreased permeability of the lamina propria and an increased stabilisation of the intestinal microbial ecosystem by promoting beneficial bacteria may further improve animal health. Additionally, there is evidence that IMP may facilitate $\mathrm{Fe}$ absorption, which is of special interest in pigs as $\mathrm{Fe}$ 
has been acknowledged as a mineral which frequently becomes deficient in pig nutrition.

However, results of studies pertaining to biological effects of nucleotides in single-stomached animals are equivocal. In most studies, commercially available yeast products have been assayed both under in vitro and in vivo conditions. Since these yeast culture products contain variable amounts of nucleotides in addition to viable cells, cell wall components, and parts of the medium on which the yeast cells were grown, it is difficult to assign the observed biological effects exclusively to specific nucleotides present in these products. Studies in

Table 5. Zootechnical effects of nucleotide supplementation to diets of pigs compared with the control diet

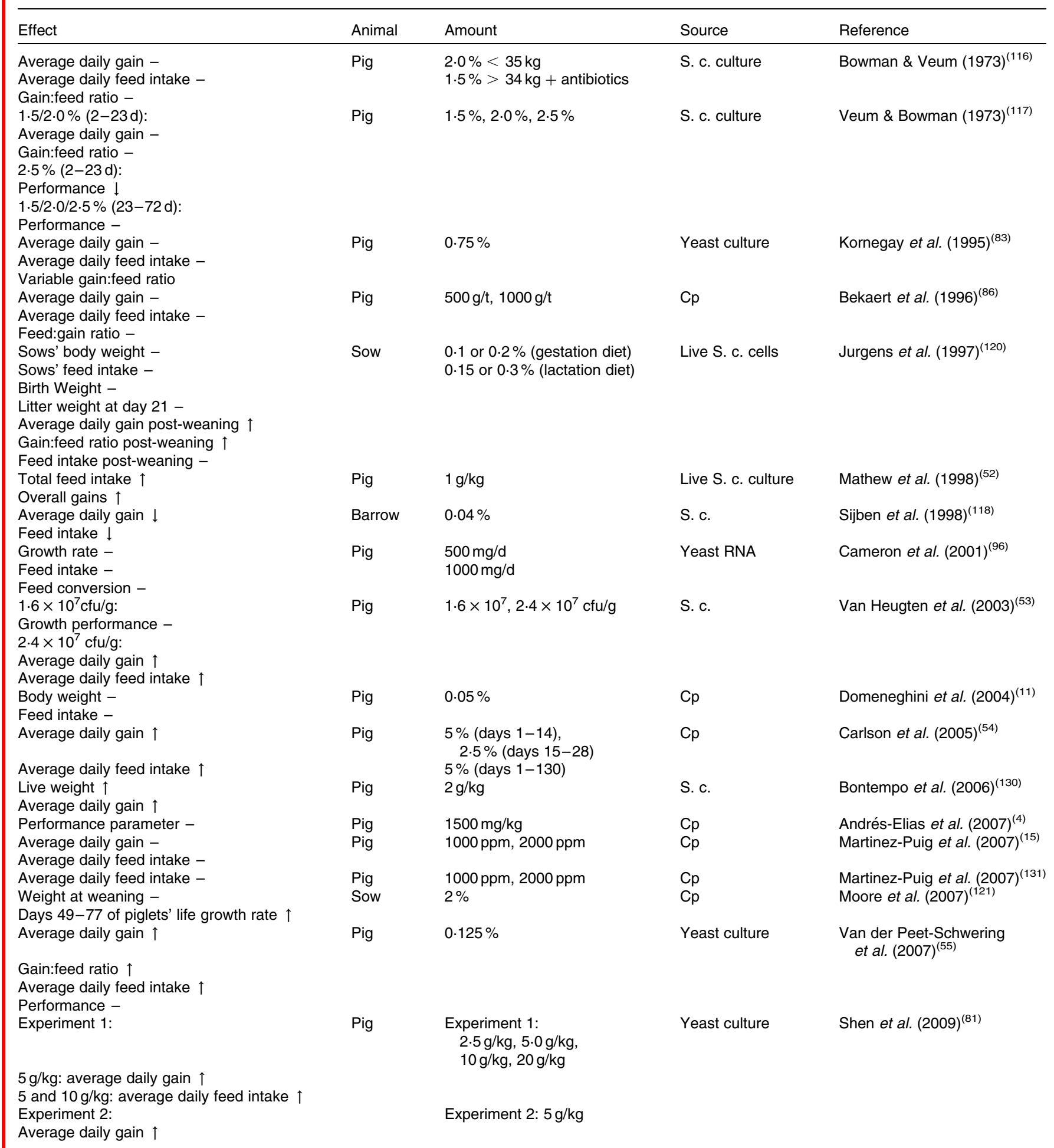

-, No effect; S.c., Saccharomyces cerevisiae; $\downarrow$, decrease; Cp, commercial product containing nucleotides; $\uparrow$, increase; cfu, colony-forming units; ppm, parts per million. 
which the biological effects of purified sources of nucleotides, alone or in combination, were assayed are scarce. Therefore, further research should be directed to the evaluation of the efficiency of purified nucleotides, including the effects of varying concentrations and different combinations of nucleotides. In addition, future research should also focus on the potential associated effects of nucleotides if supplied in combination with other bioactive substances, for example, glutamine.

Finally, advanced knowledge about the contents of nucleotides present in commonly used feed components would facilitate the development of feeding strategies to meet animals' requirements for nucleotides, in particular in young animals suffering from various kinds of stress.

\section{Acknowledgements}

The present review received no specific grant from any funding agency in the public, commercial or not-forprofit sectors.

We thank Ingrid Neff for assisting in preparing the manuscript.

Conceptualisation and implementation of the manuscript was performed by R. M. and E. B. The manuscript was written by N. S. All authors reviewed the manuscript and approved submission. There are no conflicts of interest.

\section{References}

1. Bager F, Aarestrup FM \& Wegener HC (2000) Dealing with antimicrobial resistance - the Danish experience. Can J Anim Sci 80, 223-228.

2. Cummins AG, Steele TW, LaBrooy JT, et al. (1988) Maturation of the rat small intestine at weaning: changes in epithelial cell kinetics, bacterial flora, and mucosal immune activity. Gut 29, $1672-1679$.

3. Pluske JR, Hampson DJ \& Williams IH (1997) Factors influencing the structure and function of the small intestine in the weaned pig: a review. Livest Prod Sci 51, 215-236.

4. Andrés-Elias N, Pujols J, Badiola I, et al. (2007) Effect of nucleotides and carob pulp on gut health and performance of weanling piglets. Livest Sci 108, 280-283.

5. Clifford AJ \& Story DL (1976) Levels of purines in foods and their metabolic effects in rats. J Nutr 106, 435-442.

6. Mateo CD, Peters DN \& Stein HH (2004) Nucleotides in sow colostrum and milk at different stages of lactation. J Anim Sci 82, 1339-1342.

7. Uauy R (1989) Dietary nucleotides and requirements in early life. In Textbook of Gastroenterology and Nutrition in Infancy, 2nd ed., pp. 265-280 [E Lebenthal, editor]. New York: Raven Press, Ltd.

8. Cosgrove M (1998) Nucleotides. Nutrition 14, 748-751.

9. Carver JD \& Walker WA (1995) The role of nucleotides in human nutrition. $J$ Nutr Biochem 6, 58-72.

10. Taylor-Pickard J (2008) Dietary nucleotides - the foundation for the future. Int Pig Top 23, 7-9.

11. Domeneghini C, Di Giancamillo A, Savoini G, et al. (2004) Structural patterns of swine ileal mucosa following L-glutamine and nucleotide administration during the weaning period. An histochemical and histometrical study. Histol Histopathol 19, 49-58.
12. Bustamante SA (1990) Intestinal hyperemia evoked by nucleotides in newborn swine. Pediatr Res 27, 102(A).

13. Nagafuchi S, Katayanagi T, Nakagawa E, et al. (1997) Effects of dietary nucleotides on serum antibody and splenic cytokine production in mice. Nutr Res 17, 1163-1174.

14. Novak DA, Carver JD \& Barness LA (1994) Dietary nucleotides affect hepatic growth and composition in the weanling mouse. JPEN J Parenter Enteral Nutr 18, 62-66.

15. Martinez-Puig D, Manzanilla EG, Morales J, et al. (2007) Dietary nucleotide supplementation reduces occurrence of diarrhoea in early weaned pigs. Livest Sci 108, 276-279.

16. Gil A, Corral E, Martínez A, et al. (1986) Effects of the addition of nucleotides to an adapted milk formula on the microbial pattern of faeces in at term newborn infants. J Clin Nutr Gastroenterol 1, 127-132.

17. Uauy R, Stringel G, Thomas R, et al. (1990) Effect of dietary nucleosides on growth and maturation of the developing gut in the rat. J Pediatr Gastroenterol Nutr 10, 497-503.

18. Carver JD (1994) Dietary nucleotides: cellular immune, intestinal and hepatic system effects. J Nutr 124, 144S-148S.

19. Larson BL \& Hegarty HM (1979) Orotic acid in milks of various species and commercial dairy products. J Dairy Sci 62 , 1641-1644.

20. Nelson DL \& Cox MM (2008) Nucleotides and nucleic acids. In Lebninger Principles of Biochemistry, 5th ed., pp. 271-298 [DL Nelson and MM Cox, editors]. New York: WH Freeman and Company.

21. Gil A, Gomez-Leon C \& Rueda R (2007) Exogenous nucleic acids and nucleotides are efficiently hydrolysed and taken up as nucleosides by intestinal explants from suckling piglets. Br J Nutr 98, 285-291.

22. Boza J (1998) Nucleotides in infant nutrition. Monatsschr Kinderbeilkd 146, Suppl. 1, S39-S48.

23. Chu SW (1991) Nucleotides: biochemistry and metabolism. Sem Pediat Gastr Nutr 2, 6-11.

24. Savaiano DA \& Clifford AJ (1981) Adenine, the precursor of nucleic acids in intestinal cells unable to synthesize purines de novo. J Nutr 111, 1816-1822.

25. LeLeiko NS, Bronstein AD, Baliga BS, et al. (1983) De novo purine nucleotide synthesis in the rat small and large intestine: effect of dietary protein and purines. $J$ Pediatr Gastroenterol Nutr 2, 313-319.

26. Gil A \& Uauy R (1995) Nucleotides and related compounds in human and bovine milks. In Handbook of Milk Composition, pp. 436-464 [RG Jensen, editor]. San Diego: Academic Press, Inc.

27. Sanderson IR \& He Y (1994) Nucleotide uptake and metabolism by intestinal epithelial cells. J Nutr 124, 131S-137S.

28. Harms V \& Stirling CE (1977) Transport of purine nucleotides and nucleosides by in vitro rabbit ileum. Am J Physiol Gastrointest Liver Physiol 233, G47-G55.

29. Bronk JR \& Hastewell JG (1988) The transport and metabolism of naturally occurring pyrimidine nucleosides by isolated rat jejunum. $J$ Physiol 395, 349-361.

30. Plagemann PGW, Marz R \& Wohlhueter RM (1978) Uridine transport in Novikoff rat hepatoma cells and other cell lines and its relationship to uridine phosphorylation and phosphorolysis. J Cell Physiol 97, 49-72.

31. Marz R, Wohlhueter RM \& Plagemann PGW (1979) Purine and pyrimidine transport and phosphoribosylation and their interaction in overall uptake by cultured mammalian cells. J Biol Chem 254, 2329-2338.

32. Quan R \& Uauy R (1991) Nucleotides and gastrointestinal development. Sem Pediat Gastr Nutr 2, 3-6.

33. Markiewicz A, Kaminski M, Chocilowski W, et al. (1983) Circadian rhythms of four marker enzymes activity of the jejunal villi in man. Acta Histochem 72, 91-99. 
34. Morley DJ, Hawley DM, Ulbright TM, et al. (1987) Distribution of phosphodiesterase I in normal human tissues. J Histochem Cytochem 35, 75-82.

35. Weickmann JL, Elson M \& Glitz DG (1981) Purification and characterization of human pancreatic ribonuclease. Biochemistry 20, 1272-1278.

36. Holdsworth G \& Coleman R (1975) Enzyme profiles of mammalian bile. Biochim Biophys Acta 389, 47-50.

37. Bronk JR \& Hastewell JG (1987) The transport of pyrimidines into tissue rings cut from rat small intestine. J Physiol 382, 475-488.

38. Salati LM, Gross CJ, Henderson LM, et al. (1984) Absorption and metabolism of adenine, adenosine- $5^{\prime}$-monophosphate, adenosine and hypoxanthine by the isolated vascularly perfused rat small intestine. J Nutr 114, 753-760.

39. Barness LA (1994) Dietary sources of nucleotides - from breast milk to weaning. J Nutr 124, 128S-130S.

40. Kulkarni AD, Rudolph FB \& van Buren CT (1994) The role of dietary sources of nucleotides in immune function: a review. J Nutr 124, 1442S-1446S.

41. Paubert-Braquet M, Dupont C, Hedef N, et al. (1992) Quantification of nucleotides in human milk and their effects on cytokine production by murine fibroblasts, J774A1 macrophages and human monocytes. In Foods, Nutrition and Immunity, 1st ed., pp. 22-34 [M Paubert-Braquet, C Dupont and R Paoletti, editors]. Basel: Karger.

42. Zivkovic D (2007) Investigations on 2,7-diamino-9-fluorenol photochemistry. PhD Thesis, University of Basel.

43. Poggioli J, Mauger J-P \& Claret M (1986) Effect of cyclic AMP-dependent hormones and $\mathrm{Ca}^{2+}$-mobilizing hormones on the $\mathrm{Ca}^{2+}$ influx and polyphosphoinositide metabolism in isolated rat hepatocytes. Biochem J 235, 663-669.

44. Lee DN, Liu SR, Chen YT, et al. (2007) Effects of diets supplemented with organic acids and nucleotides on growth, immune responses and digestive tract development in weaned pigs. J Anim Physiol Anim Nutr (Berl) 91, 508-518.

45. Rudolph FB, Kulkarni AD, Schandel VB, et al. (1984) Involvement of dietary nucleotides in T-lymphocyte function. $A d v$ Exp Med Biol 165B, 175-178.

46. Carver JD (1999) Dietary nucleotides: effects on the immune and gastrointestinal systems. Acta Paediatr Suppl 88, 83-88.

47. Xu RJ (2003) Composition of porcine milk. In The Neonatal Pig - Gastrointestinal Physiology and Nutrition, pp. 213-246 [RJ Xu and P Cranwell, editors]. Nottingham: Nottingham University Press.

48. Isaacs CE \& Thormar H (1991) The role of milk-derived antimicrobial lipids as antiviral and antibacterial agents. Adv Exp Med Biol 310, 159-165.

49. Hartmann PE \& Holmes MA (1989) Sow lactation. In Manipulating Pig Production II, pp. 72-79 [JL Barnett and DP Hennessy, editors]. Melbourne: Australasian Pig Science Association Publication

50. Bardocz S (1993) The role of dietary polyamines. Eur J Clin Nutr 47, 683-690.

51. Schlimme E, Martin D \& Meisel H (2000) Nucleosides and nucleotides: natural bioactive substances in milk and colostrum. Br J Nutr 84, S59-S68.

52. Mathew AG, Chattin SE, Robbins CM, et al. (1998) Effects of a direct-fed yeast culture on enteric microbial populations, fermentation acids, and performance of weanling pigs. J Anim Sci 76, 2138-2145.

53. Van Heugten E, Funderburke DW \& Dorton KL (2003) Growth performance, nutrient digestibility, and fecal microflora in weanling pigs fed live yeast. J Anim Sci 81, $1004-1012$

54. Carlson MS, Veum TL \& Turk JR (2005) Effects of yeast extract versus animal plasma in weanling pig diets on growth performance and intestinal morphology. I Swine Health Prod 13, 204-209.

55. Van der Peet-Schwering CMC, Jansman AJM, Smidt H, et al (2007) Effects of yeast culture on performance, gut integrity, and blood cell composition of weanling pigs. J Anim Sci $\mathbf{8 5}$, 3099-3109.

56. Kojima K (1974) Safety evaluation of disodium $5^{\prime}$-inosinate, disodium 5'-guanylate and disodium 5'-ribonucleotide. Toxicology 2, 185-206.

57. Maloney D (1998) Yeasts. In Kirk-Othmer Encyclopedia of Chemical Technology, 4th ed., pp. 761-788 [JI Kroschwitz and M Howe-Grant, editors]. New York: John Wiley and Sons, Inc

58. Ingledew WM (1999) Yeast - could you base a business on this bug? In Biotechnology in the Feed Industry. Proceedings of Alltech's 15th Annual Symposium, pp. 27-47 [TP Lyons and KA Jacques, editors]. Nottingham: Nottingham University Press.

59. Tibbetts GW (2002) Nucleotides from yeast extract: potential to replace animal protein sources in food animal diets. In Nutritional Biotechnology in the Feed and Food Industries Proceedings of Alltech's 18th Annual Symposium, pp. 435-443 [TP Lyons and KA Jacques, editors]. Nottingham: Nottingham University Press.

60. Mateo CD \& Stein HH (2004) Nucleotides and young animal health: can we enhance intestinal tract development and immune function? In Nutritional Biotechnology in the Feed and Food Industries. Proceedings of Alltech's 20th Annual Symposium, pp. 159-168 [TP Lyons and KA Jacques, editors]. Nottingham: Nottingham University Press.

61. Lautt WW, Legare DJ \& D'Almeida MS (1985) Adenosine as putative regulator of hepatic arterial flow (the buffer response). Am J Physiol Heart Circ Physiol 248, H331-H338.

62. Ogoshi S, Iwasa M, Kitagawa S, et al. (1988) Effects of total parenteral nutrition with nucleoside and nucleotide mixture on d-galactosamine-induced liver injury in rats. JPEN $J$ Parenter Enteral Nutr 12, 53-57.

63. Ohyanagi H, Nishimatsu S, Kanbara Y, et al. (1989) Effects of nucleosides and a nucleotide on DNA and RNA syntheses by the salvage and de novo pathway in primary monolayer cultures of hepatocytes and hepatoma cells. JPEN J Parenter Enteral Nutr 13, 51-58.

64. Yamaguchi T, Takada Y, Shimahara Y, et al. (1992) A mixture of nucleosides and a nucleotide alters hepatic energy metabolism 24 hours after hepatectomy in rabbits. J Nutr 122, 340-344

65. Ogoshi S, Iwasa M, Yonezawa T, et al. (1985) Effect of nucleotide and nucleoside mixture on rats given total parenteral nutrition after $70 \%$ hepatectomy. JPEN J Parenter Enteral Nutr 9, 339-342.

66. Jin MB, Yamaguchi T, Shimahara Y, et al. (1996) Significance of nucleosides and a nucleotide mixture infusion on hepatic energy metabolism of $70 \%$ hepatectomized rabbits in postoperative phase. JPEN J Parenter Enteral Nutr 20 211-214.

67. Sanchez-Pozo A, Pita ML, Martinez A, et al. (1986) Effects of dietary nucleotides upon lipoprotein pattern of newborn infants. Nutr Res 6, 763-771.

68. Gil A (1983) Human milk nucleotides: influences on the newborn metabolism. In Abstract of Symposia XVI International Congress of Pediatrics, Symposium Human milk: Recent knowledge, pp. 82. Manila: Philippines.

69. Von Euler LH, Rubin RJ \& Handschumacher RE (1963) Fatty livers induced by orotic acid. II. Changes in nucleotide metabolism. J Biol Chem 238, 2464-2469.

70. Windmueller HG \& Levy RI (1967) Total inhibition of hepatic $\beta$-lipoprotein production in the rat by orotic acid. $J$ Biol Chem 242, 2246-2254. 
71. Pottenger LA \& Getz GS (1971) Serum lipoprotein accumulation in the livers of orotic acid-fed rats. J Lipid Res $\mathbf{1 2}$, 450-459.

72. Ramírez M, Hortelano P, Boza J Jr, et al. (1991) Effect of dietary nucleotides and orotate on the blood levels of prostacyclin $\left(\mathrm{PGI}_{2}\right)$ and thromboxane $\left(\mathrm{TXA}_{2}\right)$ in the weanling rat. Prostaglandins Leukot Essent Fatty Acids 43, 49-54.

73. Boza J, Jimenez J, Faus MJ, et al. (1992) Influences of postnatal age and dietary nucleotides on plasma fatty acids in the weanling rat. JPEN J Parenter Enteral Nutr 16, 322-326.

74. Jimenez J Jr, Boza J, Suarez MD, et al. (1992) Changes in fatty acid profiles of red blood cell membranes mediated by dietary nucleotides in weanling rats. J Pediatr Gastroenterol Nutr 14, 293-299.

75. Torres MI, Fernandez MI, Gil A, et al. (1997) Effect of dietary nucleotides on degree of fibrosis and steatosis induced by oral intake of thioacetamide. Dig Dis Sci 42, 1322-1328.

76. Fontana L, Moreira E, Torres MI, et al. (1999) Effects of dietary polyunsaturated fatty acids and nucleotides on tissue fatty acid profiles of rats with carbon tetrachloride-induced liver damage. Clin Nutr 18, 93-101.

77. Sato N, Nakano T, Kawakami $\mathrm{H}$, et al. (1999) In vitro and in vivo effects of exogenous nucleotides on the proliferation and maturation of intestinal epithelial cells. J Nutr Sci Vitaminol 45, 107-118.

78. Ortega MA, Gil A \& Sánchez-Pozo A (1995) Maturation status of small intestine epithelium in rats deprived of dietary nucleotides. Life Sci 56, 1623-1630.

79. Arnaud A, Lopez-Pedrosa JM, Torres MI, et al. (2003) Dietary nucleotides modulate mitochondrial function of intestinal mucosa in weanling rats with chronic diarrhea. $J$ Pediatr Gastroenterol Nutr 37, 124-131.

80. Tsujinaka T, Iijima S, Kido Y, et al. (1993) Role of nucleosides and nucleotides mixture in intestinal mucosal growth under total parenteral nutrition. Nutrition 9, 532-535.

81. Shen YB, Piao XS, Kim SW, et al. (2009) Effects of yeast culture supplementation on growth performance, intestinal health, and immune response of nursery pigs. J Anim Sci 87, 2614-2624.

82. Godlewski MM, Bierła JB, Strzałkowski A, et al. (2009) A novel cytometric approach to study intestinal mucosa rebuilding in weaned pigs fed with dietary nucleotides. Livest Sci 123, 215-220.

83. Kornegay ET, Rhein-Welker D, Lindemann MD, et al. (1995) Performance and nutrient digestibility in weanling pigs as influenced by yeast culture additions to starter diets containing dried whey or one of two fiber sources. J Anim Sci $\mathbf{7 3}$, 1381-1389.

84. Bueno J, Torres M, Almendros A, et al. (1994) Effect of dietary nucleotides on small intestinal repair after diarrhoea. Histological and ultrastructural changes. Gut 35, 926-933.

85. Nunez MC, Ayudarte MV, Morales D, et al. (1990) Effect of dietary nucleotides on intestinal repair in rats with experimental chronic diarrhea. JPEN J Parenter Enteral Nutr 14, 598-604.

86. Bekaert H, Moermans R \& Eeckhout W (1996) Effect of a live yeast culture in diets of weanling piglets on performances and frequency of diarrhoea. Ann Zootech 45, 369-376.

87. National Research Council (1998) Nutrient Requirements of Swine, 10th rev ed.. Washington, DC: National Academy Press.

88. Rincker MJ, Hill GM, Link JE, et al. (2004) Effects of dietary iron supplementation on growth performance, hematological status, and whole-body mineral concentrations of nursery pigs. J Anim Sci 82, 3189-3197.

89. Ullrey DE, Miller ER, West DR, et al. (1959) Oral and parenteral administration of iron in the prevention and treatment of baby pig anemia. J Anim Sci 18, 256-263.
90. Kernkamp HCH, Clawson AJ \& Ferneyhough RH (1962) Preventing iron-deficiency anemia in baby pigs. J Anim Sci 21, 527-532.

91. Kornegay ET (1972) Availability of iron contained in defluorinated phosphate. J Anim Sci 34, 569-572.

92. Deming JG \& Czarnecki-Maulden GL (1989) Iron bioavailability in calcium and phosphorus sources. J Anim Sci $\mathbf{6 7}$, Suppl. 1, 253A.

93. Cheney B \& Finch CA (1960) Effect of inosine on iron absorption in rats. Proc Soc Exp Biol Med 103, 37-38.

94. Faelli A \& Esposito G (1970) Effect of inosine and its metabolites on intestinal iron absorption in the rat. Biochem Pharmacol 19, 2551-2554.

95. Carver JD, Pimentel B, Cox WI, et al. (1991) Dietary nucleotide effects upon immune function in infants. Pediatrics $\mathbf{8 8}$, 359-363.

96. Cameron BF, Wong CW, Hinch GN, et al. (2001) Effects of nucleotides on the immune function of early-weaned piglets. In Digestive Physiology of Pigs. Proceedings of the 8th Symposium, pp. 66-68 [JE Lindberg and B Ogle, editors]. Wallingford: CABI Publishing.

97. Kulkarni SS, Bhateley DC, Zander AR, et al. (1984) Functional impairment of T-lymphocytes in mouse radiation chimeras by nucleotide-free diet. Exp Hematol 12, 694-699.

98. Van Buren CT, Kulkarni AD \& Rudolph FB (1983) Synergistic effect of a nucleotide-free diet and cyclosporine on allograft survival. Transplant Proc 15, Suppl. 1, 2967-2968.

99. Van Buren CT, Kulkarni AD, Schandle VB, et al. (1983) The influence of dietary nucleotides on cell-mediated immunity. Transplantation 36, 350-351.

100. Kulkarni AD, Fanslow WC, Rudolph FB, et al. (1987) Modulation of delayed hypersensitivity in mice by dietary nucleotide restriction. Transplantation 44, 847-849.

101. Pizzini RP, Kumar S, Kulkarni AD, et al. (1990) Dietary nucleotides reverse malnutrition and starvation-induced immunosuppression. Arch Surg 125, 86-89.

102. Van Buren CT, Rudolph FB, Kulkarni AD, et al. (1990) Reversal of immunosuppression induced by a protein-free diet: comparison of nucleotides, fish oil and arginine. Crit Care Med 18, Suppl. 2, S114-S117.

103. Carver JD, Cox WI \& Barness LA (1990) Dietary nucleotide effects upon murine natural killer cell activity and macrophage activation. JPEN J Parenter Enteral Nutr 14, $18-22$.

104. Fanslow WC, Kulkarni AD, van Buren CT, et al. (1988) Effect of nucleotide restriction and supplementation on resistance to experimental murine candidiasis. JPEN J Parenter Enteral Nutr 12, 49-52.

105. Kulkarni AD, Fanslow WC, Rudolph FB, et al. (1986) Effect of dietary nucleotides on response to bacterial infections. JPEN J Parenter Enteral Nutr 10, 169-171.

106. Couedel-Courteille A, Le Grand R, Tulliez M, et al. (1997) Direct ex vivo simian immunodeficiency virus (SIV)-specific cytotoxic activity detected from small intestine intraepithelial lymphocytes of SIV-infected macaques at an advanced stage of infection. J Virol 71, 1052-1057.

107. Shields JG \& Parrott DM (1985) Appearance of delayed-type hypersensitivity effector cells in murine gut mucosa. Immunology 54, 771-776.

108. Dillon SB, Dalton BJ \& MacDonald TT (1986) Lymphokine production by mitogen and antigen activated mouse intraepithelial lymphocytes. Cell Immunol 103, 326-338.

109. Lundqvist C, Melgar S, Yeung MM, et al. (1996) Intraepithelial lymphocytes in human gut have lytic potential and a cytokine profile that suggest $\mathrm{T}$ helper 1 and cytotoxic functions. J Immunol 157, 1926-1934. 
110. Salobir J, Rezar V, Pajk T, et al. (2005) Effect of nucleotide supplementation on lymphocyte DNA damage induced by dietary oxidative stress in pigs. Anim Sci 81, 135-140.

111. Tanaka R \& Mutai M (1980) Improved medium for selective isolation and enumeration of Bifidobacterium. Appl Environ Microbiol 40, 866-869.

112. Gil A (1984) Nucleotidos en la leche humana. Fundamento para su empleo en leches infantiles (Nucleotides in Human Milk. Rationale for Use in Infant Formula). Granada: Graficas del Sur.

113. Sauer N, Bauer E, Vahjen W, et al. (2010) Nucleotides modify growth of selected intestinal bacteria in vitro. Livest Sci 133, 161-163.

114. Roselli M, Britti MS, Le Huërou-Luron I, et al. (2007) Effect of different plant extracts and natural substances (PENS) against membrane damage induced by enterotoxigenic Escherichia coli K88 in pig intestinal cells. Toxicol In Vitro 21, 224-229.

115. Braun OH (1981) Effect of consumption of human milk and other formulas on intestinal bacterial flora in infants. In Textbook of Gastroenterology and Nutrition in Infancy, vol. 1. Gastrointestinal Development and Perinatal Nutrition, 1st ed., pp. 247-253 [E Lebenthal, editor]. New York: Raven Press.

116. Bowman GL \& Veum TL (1973) Saccharomyces cerevisiae yeast culture in growing-finishing swine diets. J Anim Sci $37,72-74$.

117. Veum TL \& Bowman GL (1973) Saccharomyces cerevisiae yeast culture in diets for mechanically-fed neonatal piglets and early growing self-fed pigs. J Anim Sci 37, 67-71.

118. Sijben JWC, van Vugt PNA, Swinkels JWGM, et al. (1998) Energy metabolism of immunized weanling piglets is not affected by dietary yeast. J Anim Physiol Anim Nutr 79, 153-161.

119. Yi GF, Allee GL, Toride Y, et al. (2002) Impact of glutamine, glutamate, and nucleotide on the growth performance and intestinal morphology of weaned piglets. J Anim Sci $\mathbf{8 0}$ Suppl. 1, 198.

120. Jurgens MH, Rikabi RA \& Zimmerman DR (1997) The effect of dietary active dry yeast supplement on performance of sows during gestation-lactation and their pigs. J Anim Sci 75, 593-597.

121. Moore KL, D'Souza DN \& Mullan BP (2007) Piglet growth after weaning is improved when a yeast extract is included in the diet of the lactating sow. In Manipulating Pig
Production XI, pp. 61 [JE Paterson and JA Barker, editors]. Warribee: Australasian Pig Science Association, Inc.

122. Gil A \& Sanchez-Medina F (1982) Acid soluble nucleotides of human milk at different stages of lactation. J Dairy Res 49, 301-307.

123. Matsumoto Y, Adjei AA, Yamauchi K, et al. (1995) A mixture of nucleosides and nucleotides increases bone marrow cell and peripheral neutrophil number in mice infected with methicillin-resistant Staphylococcus aureus. J Nutr 125, 817-822.

124. Yamauchi K, Adjei AA, Ameho CK, et al. (1996) A nucleoside-nucleotide mixture and its components increase lymphoproliferative and delayed hypersensitivity responses in mice. J Nutr 126, 1571-1577.

125. Nagafuchi S, Totsuka M, Hachimura S, et al. (2000) Dietary nucleotides increase the proportion of a TCR $\gamma \delta^{+}$subset of intraepithelial lymphocytes (IEL) and IL-7 production by intestinal epithelial cells (IEC); implications for modification of cellular and molecular cross-talk between IEL and IEC by dietary nucleotides. Biosci Biotechnol Biochem 64, $1459-1465$.

126. Nagafuchi S, Hachimura S, Totsuka M, et al. (2000) Dietary nucleotides can up-regulate antigen-specific Th 1 immune responses and suppress antigen-specific IgE responses in mice. Int Arch Allergy Immunol 122, 33-41.

127. Nagafuchi S, Totsuka M, Hachimura S, et al. (2002) Dietary nucleotides increase the mucosal IgA response and the secretion of transforming growth factor $\beta$ from intestinal epithelial cells in mice. Cytotechnology $\mathbf{4 0}$, $49-58$.

128. Manzano M, Gil A \& Rueda R (2004) New insights in the potential mechanism of action of nucleotides to modulate immunity. Abstract: oral presentation. J Pediatr Gastroenterol Nutr 39, S32.

129. Wang L-F, Gong X, Le G-W, et al. (2008) Dietary nucleotides protect thymocyte DNA from damage induced by cyclophosphamide in mice. J Anim Physiol Anim Nutr 92, 211-218.

130. Bontempo V, Di Giancamillo A, Savoini G, et al. (2006) Live yeast dietary supplementation acts upon intestinal morphofunctional aspects and growth in weanling piglets. Anim Feed Sci Technol 129, 224-236.

131. Martinez-Puig D, Morales J, Borda E, et al. (2007) Dietary nucleotides supplementation improves growth performance of early weaned piglets. J Anim Sci 85, Suppl. 1, 73. 